\title{
www.fmhjob.ch
}

\section{La plate-forme internet leader pour les emplois, les cabinets et les produits}
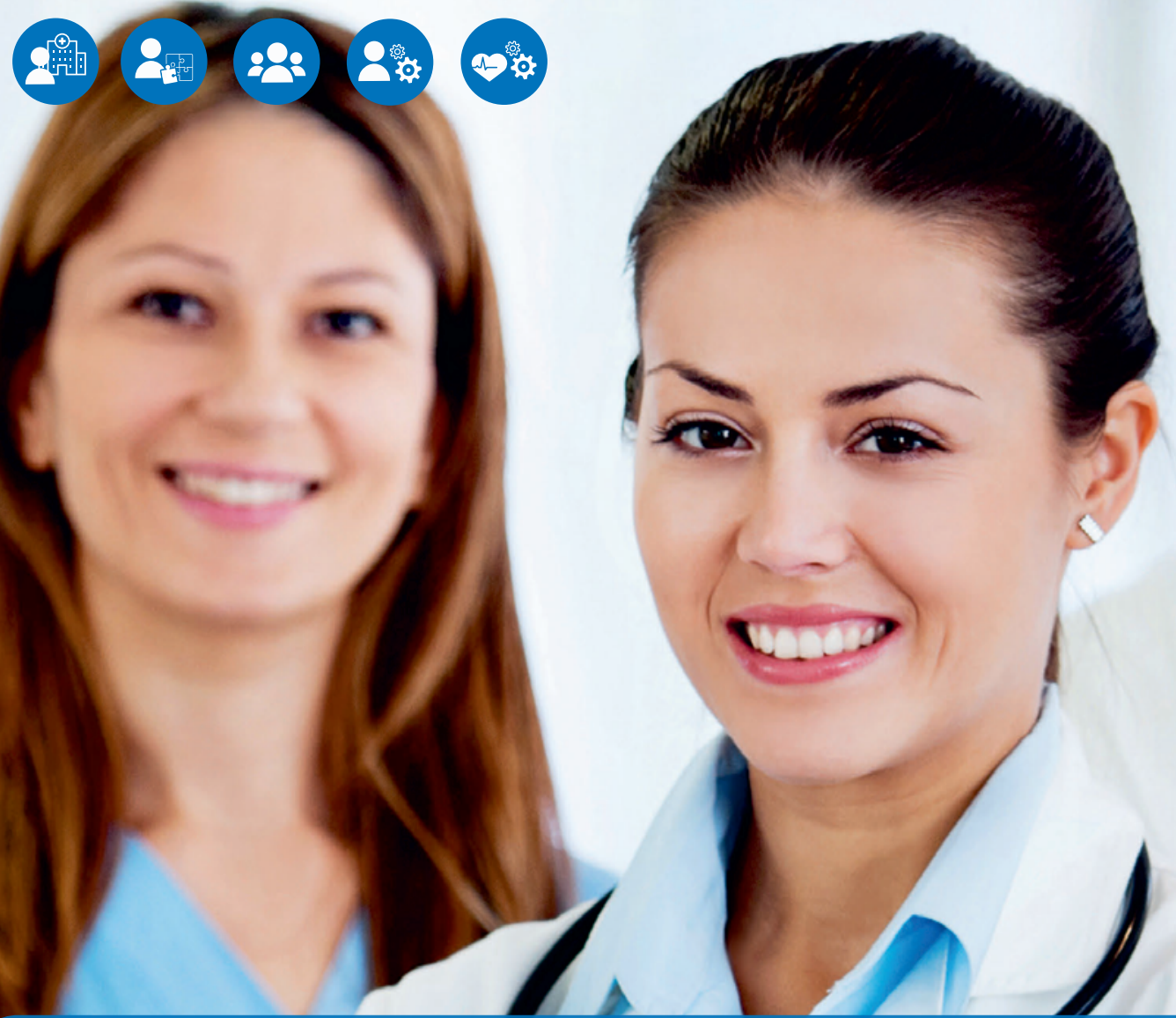

Visitez notre nouvelle plate-forme internet avec de nombreuses nouvelles fonctions, mais également des fonctions éprouvées et améliorées.

Outre des annonces et demandes d'emploi et de cabinets, vous trouverez nouvellement la rubrique partenaires de cabinet ainsi que des produits médicaux pour le cabinet.

\section{Pour les annonceurs}

- Saisie simple, modification et gestion des annonces

- Aperçu des demandeurs d'emploi (abonnement) sur internet

- Chiffre

\section{Pour les demandeurs}

- Publication simple, modification et gestion des demandes

- Nouvelles offres d'emplois, de cabinets et de produits gratuitement par e-mail

- Chiffre

\section{CONSULTING}

FMH Consulting Services AG

Avenue d'Ouchy 66, 1006 Lausanne

Tél. 0219224435

mail@fmhconsulting.ch - www.fmhservices.ch 